\title{
Repenser les « Amériques noires ». Nouvelles perspectives de la recherche afro-américaniste
}

\section{Stefania Capone}

\section{OpenEdition}

\section{Journals}

Édition électronique

URL : https://journals.openedition.org/jsa/2830

DOI : 10.4000/jsa.2830

ISSN : 1957-7842

Éditeur

Société des américanistes

\section{Édition imprimée}

Date de publication : 5 janvier 2005

Pagination : 83-91

ISSN : 0037-9174

\section{Référence électronique}

Stefania Capone, «Repenser les «Amériques noires». Nouvelles perspectives de la recherche afroaméricaniste », Journal de la Société des américanistes [En ligne], 91-1 | 2005, mis en ligne le 10 janvier 2010, consulté le 03 septembre 2022. URL : http://journals.openedition.org/jsa/2830 ; DOI : https:// doi.org/10.4000/jsa.2830 


\title{
REPENSER LES « AMÉRIQUES NOIRES ». NOUVELLES PERSPECTIVES DE LA RECHERCHE AFRO-AMÉRICANISTE
}

\author{
Stefania CAPONE *
}

En France, les études afro-américaines sont généralement considérées comme une «branche » des recherches américanistes. Or; Philippe Descola et Michel Izard (1991, p. 49) nous rappellent que le terme " américanisme » est couramment utilisé par les archéologues et les anthropologues pour désigner « l'ensemble des recherches sur les cultures autochtones de l'Amérique, pré- et postcolombiennes ». Selon ces auteurs, l'étude des sociétés modernes - notamment les études nord-américaines, afro-américaines et latino-américaines - sortirait de l'américanisme stricto sensu, puisque les Indiens n'y seraient plus considérés en tant que peuples détenteurs d'une culture « traditionnelle », mais « en tant que minorités, au même titre, par exemple, que les Noirs, les Porto-Ricains ou les Chicanos » (ibid.). L'américanisme, ou du moins «l'américanisme stricto sensu ", semble ainsi se restreindre à la seule Amérique indigène, caractéristique qui a longtemps marqué ce domaine de recherche, surtout en France.

Pour Roger Bastide $(1969$, p. 7), le peu d'intérêt montré à l'égard des études afro-américaines serait dû à une profonde divergence d'approches : contrairement aux recherches américanistes, les études sur les Noirs seraient «plus de nature sociologique qu'anthropologique ». Le précurseur des études afroaméricaines en France s'est ainsi senti obligé de justifier le bien-fondé d'un numéro spécial consacré aux recherches afro-américaines, publié sous sa direction en 1969, par l'importance « sociologique » des Noirs sur le continent américain. Et, pour se rapprocher de ses collègues américanistes, Bastide établit aussi une différence de fond entre les recherches afro-américaines en Amérique anglosaxonne et en Amérique latine : si les premières étaient marquées par les travaux des sociologues et des économistes «qui prennent en charge le problème noir pour lui trouver une solution », les secondes auraient privilégié une " perspective anthropologique », en se penchant notamment sur les survivances africaines

* CNRS, Laboratoire d'ethnologie et de sociologie comparative, UMR 7535 [stefania.capone@mae.u-paris10.fr].

Journal de la Société des Américanistes, 2005, 91-1, pp. 83-91. () Société des Américanistes. 
(ibid., pp. 7-8). Les recherches sur les religions afro-américaines, menées par Nina Rodrigues et Arthur Ramos au Brésil, par Fernando Ortiz et Lydia Cabrera à Cuba, par Jean Price-Mars et Alfred Métraux en Haïti, semblaient alors pouvoir revendiquer un droit de cité dans les cercles de l'américanisme français.

Cette même différenciation interne au domaine est encore à l'œuvre dans des textes bien plus récents. Ainsi, le Dictionnaire de l'ethnologie et de l'anthropologie distingue cinq grands « terrains » de la recherche américaniste, les études afroaméricaines étant cantonnées aux Caraïbes et au Brésil « noir » (Descola et Izard 1991, p. 53). Il est vrai que, jusqu'au début des années 1990, la recherche anthropologique française ne se montrait pas très intéressée par d'autres terrains afro-américains. La plupart des études étaient concentrées dans la région de la Caraïbe, et notamment en Martinique ou en Guadeloupe, îles qui offraient un terrain «naturel » aux chercheurs de la métropole. Rares étaient les travaux menés ailleurs, comme en Guyane (assimilée, elle, à la Caraïbe), en Colombie ou au Pérou. La plupart des anthropologues choisissaient des terrains déjà classiques, comme le Brésil, où les travaux de Bastide et de Verger avaient ouvert la voie aux jeunes chercheurs. La recherche anthropologique française restait ainsi à l'écart de pays extrêmement importants pour les études afro-américaines, tels les États-Unis ou Cuba.

L'héritage bastidien a fait que, aujourd'hui, on parle de ce domaine en termes d'« Amériques noires ». Or; cette expression, tirée d'un des plus célèbres ouvrages de Bastide (1996 [1967]), n'est pas sans ambiguïté, puisqu'il est de plus en plus difficile de cloisonner les cultures « noires » comme quelque chose qui serait le patrimoine exclusif des descendants d'Africains. L'utilisation même du terme " afro-américain » pour désigner les religions d'origine africaine pose problème, puisque, depuis fort longtemps, ces religions ne sont plus l'apanage des descendants d'Africains, mais comptent, dans leurs rangs, un grand nombre d'initiés blancs, métis et même descendants de Japonais (au Brésil) ou de Chinois (à Cuba). Les religions afro-américaines sont nées de la rencontre des croyances religieuses des esclaves africains avec les pratiques de leurs maîtres et avec les autres composantes culturelles, présentes dans les sociétés coloniales du Nouveau Monde. Mais force est de constater que l'expression « Amériques noires » continue à désigner le domaine des études afro-américaines en France.

Melville J. Herskovits (1990 [1941]) a été le premier à considérer les « Amériques noires » comme une aire culturelle à part entière, en menant de véritables recherches comparatives dont le but était d'éclairer les relations historiques et culturelles entre l'Afrique et l'Amérique ${ }^{1}$. Ce travail comparatif a été poursuivi par Roger Bastide (1996 [1967]), qui partageaient avec Arthur Ramos (1979 [1937]) un même objectif : rendre compte des influences culturelles africaines au sein des sociétés américaines, issues de l'esclavage. Le thème récurrent dans les travaux de ces trois auteurs est la question de l'acculturation qui, à travers des notions comme "syncrétisme » et "réinterprétation », essaie d'appréhender les 
processus qui ont permis la transformation des cultures africaines en cultures « afro-américaines ». Le travail de Sidney Mintz et Richard Price (1992 [1976]) est en ce sens fondamental, puisque pour la première fois les cultures afroaméricaines ne sont pas pensées comme la réminiscence - plus ou moins accomplie - d'un passé traditionnel, mais comme des créations nouvelles, résultant des nouvelles conditions de vie dans les colonies américaines.

Pendant longtemps, au Brésil, le débat a tourné autour de ces notions, jusqu'à la publication des travaux de Pierre Verger, qui ont inauguré, à la fin des années 1950, une nouvelle phase au sein des études afro-brésiliennes, mettant en avant les liens de continuité avec les cultures africaines. L'étude des religions afrobrésiliennes devient ainsi le territoire de chasse des " africanistes », une nouvelle génération d'anthropologues brésiliens qui, inspirés par le travail de Verger, iront chercher en Afrique les preuves de la fidélité de certaines pratiques religieuses afro-brésiliennes à la tradition africaine. Ainsi, à l'époque où la recherche sur les relations raciales, financée par l'UNESCO au Brésil, marquait le début, dans le sud du pays, d'une phase sociologique des études afro-brésiliennes, dans le Nordeste, on revenait à une approche culturaliste qui visait à souligner la continuité avec les cultures africaines plutôt que la rupture. De nos jours, l'influence de Verger est encore très forte au Brésil dans cette quête de l'Afrique que mènent initiés dans les cultes et anthropologues.

Les critiques portant sur cette approche ont été multiples. Lors du Congrès international des américanistes, organisé à Paris en 1976, William Bascom (1976, p. 592), à propos de la prédominance des études sur les survivances africaines dans le Nouveau Monde, affirmait que les cultures afro-américaines devaient être étudiées " regardless of any questions of origins or of how much of African culture they have retained ». La recherche des africanismes demeurait toutefois indispensable, à ses yeux, pour démontrer les apports culturels des Noirs, notamment à la société nord-américaine, et contrer de la sorte les préjugés racistes qui niaient l'existence d'une culture afro-américaine. Cette tension fondatrice entre recherche des racines culturelles africaines et étude sociologique des populations noires est encore extrêmement prégnante dans ce domaine, en France comme ailleurs.

L'étude des « civilisations africaines » en Amérique coïncide, de façon significative, avec la suppression de l'esclavage, au moment même où le Noir accède à la citoyenneté. La question était alors de savoir si le Noir pouvait ou non être intégré au sein de la Nation : était-il assimilable ou bien, au contraire, était-il porteur d'une «culture » étrangère, de modes de pensée qui empêcheraient son intégration dans la société occidentale ? Pendant longtemps, l'idée qui est ressortie des études afro-américaines était que le Noir, lorsqu'il avait su préserver les traditions africaines, appartenait à un autre monde, restant imperméable, pour reprendre les mots de Bastide, « aux idées modernes ». C'est comme si la perpétuation d'une mémoire africaine et la fidélité aux origines avaient la capacité de sortir de l'histoire celles que Bastide (1996 [1967]) appelait les « sociétés africai- 
nes » par opposition aux "sociétés nègres » qui étaient, elles, perméables à l'histoire et au changement. La formation du domaine afro-américaniste a ainsi été marquée, depuis ses débuts, par un malaise : un malaise vis-à-vis de l'idée même de mélange - physique et culturel - et de la dégénérescence inévitable qui en découlerait, mais aussi un malaise vis-à-vis d'un lien rompu avec la culture originelle, vis-à-vis de l'impossibilité de retracer, de façon probante, ses origines culturelles. Le domaine afro-américaniste a donc été construit sur une hantise : celle des origines africaines, d'un lien direct avec un territoire - l'Afrique - et avec une culture originelle. Le passé africain devient ainsi une métaphore, à la fois temporelle et spatiale, qui permet de penser un champ - l'afro-américain - dont le principal opérateur classificatoire est, sans aucun doute, l'Afrique.

En effet, les études afro-américaines ont été, depuis longtemps, marquées par ce que l'anthropologue jamaïquain David Scott (1991) a appelé « l'épistémologie vérificationniste », dont l'objectif serait d'établir si les cultures afro-américaines sont ou non " authentiquement africaines » et si leurs membres ont réellement réussi à préserver une mémoire, elle aussi "authentique», de leur passé, et notamment une mémoire de l'esclavage. Or; on est souvent confronté à une sorte de rapport mécanique entre le processus de "redécouverte » d'un passé immémorial et l'idée qu'on se fait de ce passé, qui serait « objectivement » préexistant et " authentiquement » ravivé par la mémoire collective. Roger Bastide (1970) parlait de « trous de la mémoire collective » et de la possibilité de les combler en allant chercher les éléments manquants aux sources de la tradition africaine. Pour Bastide, la mémoire collective était inscrite dans les corps noirs, ce qui a amené parfois à affïrmer la survie de l'Afrique, au sein des « sociétés nègres ", dans les mouvements du corps, dans les gestes de leurs membres, et cela malgré l'absence de toute glose explicite faisant référence à un passé africain. Dans ces analyses, la culture devient alors une sorte d'héritage génétique, ce qui épouse dangereusement les théories prônées aujourd'hui par les Africains-Américains aux ÉtatsUnis (Capone 2005).

Depuis les débuts des études afro-américaines, il s'est agi donc de retrouver l'Afrique en Amérique : les méthodes et les résultats peuvent varier, mais la tension fondatrice entre ces deux pôles est, encore de nos jours, très forte. Ainsi, si pour Arthur Ramos (1979 [1937], p. xviii), auteur en 1937 du premier ouvrage sur les "cultures noires dans le Nouveau Monde», il convient de perpétuer la méthode de l'école de Nina Rodrigues, en étudiant « les cultures africaines pour mieux comprendre le Noir du Nouveau Monde ", trente ans plus tard, Roger Bastide (1996 [1967], pp. 14-15), dans ses Amériques noires, écrit que « la meilleure méthode pour l'analyse des cultures afro-américaines consiste non pas à partir de l'Afrique pour voir ce qu'il en reste en Amérique, mais à étudier les cultures afro-américaines existantes, pour remonter progressivement d'elles à l'Afrique ». De l'Afrique à l'Amérique et vice-versa, l'une ne semble pas avoir de sens sans l'autre! 
Cela a amené à l'identification de paradigmes culturels chez les Noirs du Nouveau Monde qui fondent une sorte de « géographie des cultures africaines » où, pour reprendre les mots de Bastide (ibid., p. 18), « chacune [serait] arrivée à colorer une région, et une région seulement, d'Amérique ». Dans les colonies anglaises, la culture dominante africaine aurait ainsi été la fanti-ashanti, tandis que les colonies espagnoles et portugaises auraient été marquées par la culture yoruba et les françaises par la culture dahoméenne. Mais la quête des origines culturelles n'est pas seulement le fait des ethnologues, puisque le discours sur les origines est omniprésent chez les pratiquants des religions afro-américaines eux-mêmes. S'il y a donc une « épistémologie vérificationniste » dans ce domaine, elle est déjà présente, de façon embryonnaire, mais non moins prégnante, dans les discours des acteurs rituels. Cette convergence de discours - l'indigène et le savant - traverse l'ensemble du champ afro-américain (Capone 1999).

Le défi principal consiste donc à penser les cultures afro-américaines en tant que produits de l'Afrique autant que de l'Amérique, où rien n'est purement «africain », ni nécessairement « américain ». Ce changement de perspective pourrait nous aider à sortir de l'opposition actuelle entre le modèle de la "créolisation », défendu par les épigones de Mintz et Price, et le modèle " afrocentrique », qui met en avant la préservation d'un passé africain immémorial. Ces deux modèles, qui constituent de nos jours les deux paradigmes prédominants aux États-Unis, mettent en scène une tension qui est au fondement même du domaine afro-américaniste, entre « africanistes » et « américanistes », historiens et anthropologues. Les soi-disant « africanistes » sont, pour la plupart, des historiens " afrocentriques » ou, pour être plus exacts, "Africacentrists », comme Paul Lovejoy ou Michael Gomez, et défendent des positions tout à fait compatibles avec les positions des nationalistes culturels afroaméricains aux États-Unis, en soulignant la résistance des ethnicités africaines vis-à-vis des tentatives d'assimilation ou de « créolisation ». Les soi-disant « américanistes » sont, en revanche, les défenseurs du modèle de la « synthèse rapide ", aussi appelé le modèle de la " créolisation ", qui a été élaboré par Mintz et Price dans les années 1970 et qui serait à l'origine de la formation d'une culture afro-américaine.

Comment dépasser ce clivage ? En n'évacuant pas l'Afrique des processus de construction des sociétés et des cultures afro-américaines, sans pour autant essentialiser les identités ethniques. Ce qui frappe le plus, dans les débats nordaméricains actuels, est le fait qu'on mobilise souvent les mêmes arguments et les mêmes données pour arriver à des conclusions diamétralement opposées. Il me semble donc nécessaire aujourd'hui de sortir de ce qu'on pourrait appeler un " champ de bataille idéologique », pour conjuguer ces deux approches, en montrant comment l'anthropologie et l'histoire constituent deux facettes également essentielles de ce domaine d'études. Il faudrait ainsi abandonner les tentatives, vouées nécessairement à l'échec, qui visent à reconstruire des "passés afro- 
américains authentiques » (Scott 1991), tout en essayant de comprendre le rôle et la place de l'Afrique dans l'élaboration des cultures afro-américaines. Dans les discours des acteurs sociaux et des pratiquants des religions afro-américaines, le lien avec l'Afrique et la rupture engendrée par l'esclavage sont les deux points de référence constants : le domaine afro-américaniste se construit sur cette tension entre continuité et discontinuité, entre fidélité et trahison vis-à-vis des origines, entre " pureté » et « dégénérescence ».

Aujourd'hui une relecture du champ afro-américaniste s'impose. Il faut prendre conscience, par exemple, du potentiel réductionniste et réificatoire de notions telles que " identité ", " ethnicité » et même " culture », liées à cette " politique des origines ». Dans le domaine afro-américaniste, on est parfois obligé de rappeler que tant la notion de « race » que les prétendues « origines » ne sont que des constructions sociales et historiques bien déterminées. La même expression " culture noire », trop souvent réifiée, n'est qu'une construction indigène qui ne peut guère être transformée en outil d'analyse. Et si la "culture noire » est par définition syncrétique, l'identité « noire » est, tout comme les identités ethniques, une identité relationnelle et contingente. La comparaison du terrain brésilien avec le terrain nord-américain montre bien que ce qui est noir dans un système racial polarisé (États-Unis) sera considéré métis dans un système fondé sur un continuum de catégories raciales (Brésil).

Mais la remise en question de notions, qui sont au cœur même de notre discipline, ne s'arrête pas là. Depuis le début, les cultures afro-américaines se sont construites de façon transnationale, puisqu'il y a toujours eu un ailleurs qu'il fallait prendre en compte : l'Afrique, terre des origines, continent rêvé plus que réel, utilisé comme une sorte de banque de symboles dans laquelle puiser pour façonner de nouvelles cultures. Les afro-américanistes ont ainsi toujours dû se confronter à la transnationalisation de ces cultures, à leur "hybridité " ou " créolisation », pour reprendre les termes les plus utilisés aujourd'hui (Capone 2004). De plus, le domaine afro-américaniste nous permet aussi de remettre en question l'opposition entre tradition et modernité, entre Occident et AfroAmérique, puisque l'un a besoin de l'autre, les deux se construisant historiquement dans un rapport spéculaire (Palmié 2002). Déjà dans les années 1950, Alfred Métraux (1958) écrivait que, malgré son héritage africain, on oublie trop souvent que le vodou haïtien appartient au monde moderne et fait partie de notre propre civilisation. Les cultures afro-américaines sont ainsi un produit de notre propre histoire, l'histoire de l'Occident, et doivent être appréhendées en tant que tel.

Et, pour faire exploser définitivement les frontières internes de notre objet, nous sommes aussi obligés, aujourd'hui, de nous confronter à des pratiques religieuses qui ne sont plus limitées à leur pays d'origine et qui doivent, en conséquence, être étudiées dans une " plurilocalité ». Comme aux États-Unis, on retrouve la santería cubaine au Mexique, au Venezuela, en France ou en Espagne, 
le candomblé brésilien au Portugal et en Belgique, l'umbanda et le batuque brésiliens en Argentine et en Uruguay, pour ne citer que quelques exemples. Cela pose dans de nouveaux termes ce qui est une des caractéristiques des religions afro-américaines, dont l'étude n'a jamais pu se faire qu'en termes de réseaux, entre l'Afrique et le Brésil, ou entre les centres détenteurs des traditions africaines sur le sol américain. On peut ainsi passer d'une approche comparative, qui souligne la continuité culturelle entre l'Afrique et l'Amérique, à une nouvelle approche qui prend en compte l'espace de circulation des acteurs sociaux, des symboles et des savoirs rituels.

Les articles qui composent ce dossier illustrent bien les changements d'approche au sein du domaine afro-américaniste. Dans ce numéro, Pauline Guedj analyse le processus de réafricanisation chez les Noirs nord-américains, divisé en deux courants : un mouvement yoruba, centré autour d'Oyotunji Village et de son fondateur Adefunmi I, et un mouvement akan, qui a "revitalisé » aux États-Unis des pratiques religieuses originaires du Ghana. Ces deux mouvements participent à la constitution d'un champ religieux « africain » en Amérique du Nord, dans lequel la religion des orisha et celle des abosom coexistent en tant que systèmes de croyance apparentés. Les initiés nord-américains dans la religion akan revendiquent ainsi l'existence d'un système de croyance unique et " panafricain », fondé sur l'idée d'une unité de fond de la culture africaine.

Les articles de Silvina Testa et de Luis Nicolau Parés montrent l'importance de l'analyse de ces phénomènes religieux dans la longue durée. Partant de deux terrains différents, Cuba et Brésil, ces deux auteurs retracent une ethnohistoire des religions afro-cubaines et afro-brésiliennes qui remet en cause les mythes d'origine de la santería cubaine et du candomblé brésilien. Silvina Testa montre, à partir de l'exemple de Sagua la Grande, censée être l'un des centres traditionnels de la santería, comment cette pratique est en réalité originaire de la région occidentale de Cuba, constituant une innovation rituelle relativement récente dans cette ville. Dans son article, elle retrace le processus d'expansion progressive de la santería ou culte lucumí (d'origine yoruba), ainsi que la « lucumisation » de pratiques religieuses, comme les « reliques de famille » et le « santo à l'africaine », qui constituaient la tradition locale jusqu'au début du $\mathrm{xx}^{\mathrm{e}}$ siècle. On passe alors d'un culte familial, ancré dans le lignage biologique et sans procédure initiatique, à un culte individuel, inséré dans un lignage rituel, auquel on est intégré suite à une initiation. L'article de Luis Nicolau Parés montre, lui aussi, comment les modalités de culte qui, aujourd'hui, incarnent l'orthodoxie religieuse ne constituent pas nécessairement le premier modèle ayant forgé les pratiques religieuses afro-américaines. Cet auteur analyse ce qu'il appelle le processus de «nagoisation » au sein du candomblé de Bahia, montrant comment, jusqu'au xıx ${ }^{\mathrm{e}}$ siècle, le culte dominant était le jeje (dahoméen), dont les divinités multiples réunies dans un même temple et la hiérarchie religieuse auraient servi de modèle à la constitution des premières maisons de culte de candomblé. Cette hypothèse, fondée sur 
l'étude de documents du XIX ${ }^{\mathrm{e}}$ siècle, remet en cause la tradition orale, reprise par la plupart des auteurs, qui fait de la « nation » ketu (yoruba) le paradigme de la tradition dans le candomblé.

Le rapport direct, établi par Herskovits et Bastide, entre des pratiques religieuses afro-américaines et des cultures africaines bien déterminées est aussi remis en question par le texte de Terry Rey, qui montre l'importance de la culture bantoue dans le vodou haïtien. Il souligne l'influence de la religion populaire kongolaise, qui était déjà très marquée par le catholicisme bien avant la traite négrière, dans la pratique des pèlerinages pour les lwa haïtiens. Les cultures bantoues se révèlent, de la sorte, beaucoup plus prégnantes dans les processus de constitution de ces phénomènes religieux que ce qui est normalement affirmé dans les études afro-américaines ${ }^{2}$.

Ces articles ouvrent de nouvelles perspectives à la recherche afroaméricaniste, montrant la grande richesse et les changements en acte dans ce champ.

\section{NOTES}

1. Malgré les reproches qui peuvent être adressés au travail d'Herskovits, sa contribution aux études afro-américaines a été fondamentale. Bien que très critique à l'égard d'Herskovits, Roger Bastide (1969, p. 12) reconnaît son apport essentiel, notamment à l'organisation et à la systématisation de la recherche afro-américaniste. 2000).

2. Pour une critique de la prédominance du modèle yoruba dans ces études, voir Capone (1999 et

\section{RÉFÉRENCES BIBLIOGRAPHIQUES}

\section{BASCOM William}

1976 "Afro-American Studies », in Actes du XLII Congrès international des américanistes, Paris, 2-9 septembre 1976, vol. VI, pp. 591-595.

BASTIDE Roger

1969 "État actuel et perspectives d'avenir des recherches afro-américaines », Journal de la Société des Américanistes, LVIII, pp. 7-29.

1970 "Mémoire collective et sociologie du bricolage ", L'Année sociologique, $\mathrm{III}^{\mathrm{e}}$ série, 21, pp. 65-108.

1996 Les Amériques noires, L'Harmattan, Paris [1967].

CAPONE Stefania

1999 La quête de l'Afrique dans le candomblé : pouvoir et tradition au Brésil, Karthala, Paris.

2000 «Entre Yoruba et Bantu : l'influence des stéréotypes raciaux dans les études afro-américaines ", Cahiers d'études africaines, 157, pp. 55-77. 
2004 "À propos des notions de globalisation et transnationalisation », Civilisations, LI (1-2), numéro spécial "Religions transnationales ", pp. 9-22, Bruxelles.

2005 Les Yoruba du Nouveau Monde : religion, ethnicité et nationalisme noir aux États-Unis, Karthala, Paris [sous presse].

Descola Philippe et Michel Izard

1991 "Les recherches sur l'Amérique », in P. Bonte et M. Izard, éds, Dictionnaire de l'ethnologie et de l'anthropologie, Presses universitaires de France, Paris, pp. 49-53.

Herskovits Melville J.

1990 The Myth of the Negro Past, Beacon Press, Boston [1941].

MÉTraux, Alfred

1958 Le vaudou haïtien, Gallimard, Paris.

Mintz Sydney et Richard PRICE

1992 The birth of African-American culture: an anthropological perspective, Beacon Press, Boston [1976].

PALmí́ Sthephan

2002 Wizards and scientists : exploration in Afro-Cuban modernity and tradition, Duke University Press, Durham/London.

Ramos Arthur

1979 As culturas negras no Novo Mundo, Civilização Brasileira, Rio de Janeiro [1937].

ScotT David

1991 « That event, this memory : notes on an anthropology of African diasporas in the New World ", Diaspora, 1, pp. 261-284. 